\title{
Los rituales del Estado colonial y las élites andinas
}

Les rituels de l'État colonial et des élites andines

The rituals of the colonial state and the Andean elites

Iris Gareis

\section{OpenEdition \\ Journals}

Edición electrónica

URL: http://journals.openedition.org/bifea/3325

DOI: $10.4000 /$ bifea.3325

ISSN: 2076-5827

Editor

Institut Français d'Études Andines

Edición impresa

Fecha de publicación: 1 abril 2008

Paginación: 97-109

ISSN: 0303-7495

Referencia electrónica

Iris Gareis, « Los rituales del Estado colonial y las élites andinas », Bulletin de l'Institut français d'études andines [En línea], 37 (1) | 2008, Publicado el 01 octubre 2008, consultado el 10 diciembre 2020. URL http://journals.openedition.org/bifea/3325 ; DOI : https://doi.org/10.4000/bifea.3325

\section{(c) (i) $\odot$}

Les contenus du Bulletin de l'Institut français d'études andines sont mis à disposition selon les termes de la licence Creative Commons Attribution - Pas d'Utilisation Commerciale - Pas de Modification 4.0 International. 


\title{
Los rituales del Estado colonial y las élites andinas
}

\author{
Iris Gareis*
}

\section{Resumen}

Al igual que el imperio de los incas, el Estado colonial creó sus propios rituales políticos. Estos fueron un eje importante en la articulación del poder en los Andes, al proporcionar un espacio para negociar las relaciones de poder entre el Virrey y las élites andinas. A los curacas les tocó un rol de suma importancia en la colonia, ya que fueron los intermediarios entre el poder estatal y la población autóctona. Consecuentemente tomaron parte en los rituales políticos del virreinato. Sin embargo, las élites andinas no se contentaron con el rol de comparsa en la escenificación del poder colonial, sino que supieron aprovechar a su vez los rituales virreinales para resaltar su elevada posición social y consolidar su poder político dentro del Estado colonial.

Palabras clave: rituales políticos, élites andinas, curacas, política colonial, vida ceremonial, autorepresentación indígena

\section{Les rituels de I’État colonial et des élites andines}

\section{Résumé}

Tout comme l'Empire des Incas, I'État colonial créa ses propres rituels politiques. Ceux-ci eurent une grande importance pour l'articulation du pouvoir dans les Andes en offrant un espace pour négocier les relations de pouvoir entre le vice-roi et l'élite andine. Les curacas ont joué un rôle de premier plan dans le système colonial en tant qu'intermédiaires entre le pouvoir étatique et la population indienne. Aussi les curacas ont-ils participé aux rituels politiques de la vice-royauté. Mais ils ne se sont pas contentés d'un rôle de figurants dans la mise en scène du pouvoir colonial ; de fait, ils ont utilisé les rituels de la viceroyauté pour mettre en évidence leur position sociale élevée et pour consolider leur pouvoir politique au sein de l'État colonial.

Mots clés : rituels politiques, l'élite andine, curacas, politique coloniale, vie cérémonielle, autoreprésentation indigène

Instituto de Antropología (Frankfurt am Main). E-mail: gareis@em.uni-frankfurt.de

Agradezco la lectura del manuscrito y las sugerencias a la Dra. María Susana Cipolletti. 


\title{
The rituals of the colonial state and the Andean elites
}

\begin{abstract}
After the fall of the Inca Empire, the colonial state created political rituals of its own. These rituals were important for the articulation of power relations in the Andes. They offered a space for communication and negotiation articulating the different levels of the colonial society. As intermediaries between the state and the indigenous population, the Andean elites were of great importance for the colonial system. As a consequence, they also played a part in the political rituals of the colonial state. The Andean elites were, however, not content with the rôle of supernumeraries in the staging of colonial power and used the political rituals of the colony to highlight their social standing and to consolidate their own political power within the colonial state.
\end{abstract}

Key words: political rituals, Andean elites, curacas, colonial politics, ceremonial life, indigenous selfrepresentation

\section{INTRODUCCIÓN. RITUALES POLÍTICOS EN LA TRANSICIÓN DEL ESTADO INCA AL RÉGIMEN COLONIAL}

En la época precolombina, el estado incaico era representado en gran medida a través de sus rituales políticos, dado que estas fiestas reafirmaban tanto la cohesión entre soberano inca y población como entre hombres y poderes sobrenaturales. Sin embargo, como consecuencia de la llegada de los españoles y del subsiguiente declive del Estado inca, los rituales estatales perdieron su importancia, aunque no pasaron al olvido inmediatamente. Es de recordar que las élites incaicas no se habían extinguido, más bien se incorporaron poco a poco a la sociedad colonial, ocupando el nivel superior entre la población indígena y cumpliendo con una función similar a la que prevalecía antes de la conquista española. Especialmente en el Cusco, las élites del antiguo imperio incaico siguieron teniendo mucho respaldo de la población indígena. El Estado colonial, a su vez, generó nuevos rituales, algunos de los cuales paulatinamente formaron una síntesis entre elementos precolombinos y europeos. Al igual que en la época precolombina, los rituales políticos coloniales apuntaban a la integración de la población en el Estado, pero desde luego con la diferencia que en la Colonia se trataba de dos sistemas culturales completamente diferentes, mientras que en el Incanato los pueblos sometidos por los incas compartían con éstos la mayoría de los elementos culturales. En la época colonial —al igual que en el periodo precolombino- la comunicación entre el poder estatal y la población local se organizó en gran medida mediante rituales políticos. Por lo tanto, hubo poca diferencia entre los estados precolombino y colonial en cuanto a la función de estos rituales. Además, ambas sociedades se caracterizaban por una estrecha vinculación de lo religioso con el ámbito político y una muy elaborada vida ceremonial que funcionaba como eje de interrelación entre estos ámbitos. En ambos sistemas políticos hubo rituales que, además de establecer la comunicación entre los niveles estatal y local, también transmitieron la voluntad del soberano a la población1. Adicionalmente, al conectar los

1 Esto equivale a dos modelos distintos de comunicación: en el primer caso se trata de un intercambio entre los diversos niveles políticos. En el segundo caso, el modelo de comunicación es diferente, porque la información se transmite desde las capas dirigentes hacia los niveles locales; por lo tanto, el traslado de la información es unidireccional. 
diferentes niveles, estos rituales contribuyeron a la cohesión del Estado, ya que abrieron un espacio en el cual los diferentes agentes políticos podían comunicarse. Es decir, los rituales políticos proporcionaron, de cierto modo, un lugar para negociar las relaciones entre los diversos grupos de la sociedad². Es de añadir, además, que la situación de comunicación tal como se daba en los rituales políticos, involucraba siempre necesariamente a todos los participantes, incluso a los espectadores. Aunque en un primer momento podría parecer que los observadores no tienen importancia alguna, sin ellos el ritual carecería de sentido, ya que los espectadores por su sola presencia confirman que en efecto se ha realizado el ritual.

Como en el estado inca, también en la época colonial las autoridades políticas indígenas fueron el eje entre Estado y población. En esta red de relaciones complejas, las élites andinas desempeñaron un papel principal en el funcionamiento del Estado colonial, puesto que sin ellas no hubiera sido posible el sistema tributario y mucho menos el reclutamiento de la mano de obra indígena para la mit'a3 . Si bien en el virreinato del Perú a los rituales políticos ya no les correspondió la misma importancia primordial que los había caracterizado en la época precolombina, los rituales siguieron cumpliendo con funciones muy parecidas como en el Incanato. En primer lugar, ofrecieron un espacio de comunicación entre individuo y autoridades coloniales por un lado y entre la comunidad indígena y el Estado colonial por otro. Como medio de comunicación, los rituales políticos transmitieron nociones de poder y autoridad coloniales. Al comunicar la política colonial a la población del virreinato peruano, los rituales fueron un eje importante en la articulación del poder en los Andes. De esta manera, también proporcionaron un espacio para negociar las relaciones de poder entre el Virrey como representante del monarca español y los curacas como representantes de los súbditos andinos. La participación de las élites andinas en los rituales del virreinato, contribuyó además a la integración de las autoridades autóctonas en el sistema colonial y por lo tanto también a la consolidación de éste.

A continuación, me ocuparé de varios problemas. En primer lugar quisiera presentar brevemente los rituales políticos del Estado colonial; luego, enfocaré el rol adscrito por el poder colonial a las élites andinas en estos rituales; y finalmente me preguntaré en qué medida las élites andinas lograron apropiarse de los rituales políticos estatales.

\section{RITUALES POLÍTICOS COLONIALES Y ÉLITES ANDINAS}

Es evidente que los rituales políticos se caracterizan por tener dos vertientes simultáneas: su importancia en el ámbito religioso como también en la esfera política de la sociedad. Ampliando las definiciones de Bell (1997: 128), Bizeul (2000: 18) y Boholm (1996: 3), los rituales políticos pueder ser definidos como prácticas ceremoniales o también como eventos sociales iterativos, concernientes al orden político que representan y constituyen dicho orden. Este tipo de rituales, desde luego, se presenta con mayor frecuencia en sistemas políticos legitimados por la religión, como por ejemplo la monarquía española de esa época que se basaba en la idea de la gracia divina iluminando a sus monarcas.

2 Con respecto a las funciones y diferentes aspectos de rituales políticos en general, consúltese por ejemplo Boholm (1996: 1-6).

3 Ya en la época colonial temprana, Polo de Ondegardo (1916 [1571]: 99 ss.) hizo hincapié en la diferencia fundamental entre la mit'a en el Incanato y la mit'a colonial. Los mit'ayuq (mitayos) del imperio de los incas tan solo contribuían por cierto tiempo con su mano de obra, mientras que la mit'a en la Colonia consistía también en la entrega de tributos. Existen numerosos trabajos sobre la institución colonial de la mit'a, especialmente sobre la mit'a de minas. Con respecto a este tema, véanse por ejemplo Murra (1982), Oberem (1990: 499-504) y Wiedner (1960). 
Entre los rituales políticos del virreinato, es posible distinguir dos tipos diferentes: los rituales introducidos por los españoles y los rituales precolombinos que fueron adaptados a la situación colonial. Entre los rituales introducidos por los españoles, aquellos que tuvieron lugar al tomar posesión de un terreno fueron quizá los más llamativos. En el Incanato no existía la noción de propiedad de la tierra de la misma manera que en España ${ }^{4}$. Por eso, tampoco hubiesen tenido sentido unos rituales de posesión en los Andes precolombinos. En cambio, en España estos rituales fueron de suma importancia en la época medieval y la edad moderna, lo cual probablemente tenía mucho que ver con la situación en la Península y el clima de fervor reconquistador en esta época. Además, los rituales de posesión adquirieron todavía más importancia en la época de la Conquista, dado que sirvieron para formalizar la toma de posesión de las tierras americanas (Caillavet, 1990; Gareis, 2003: 139-140; Lienhard, 1992: 26-31, 39-40; Seed, 1995: 2-3, 70 ss.). Es interesante notar que se efectuaban ritos idénticos en la toma de posesión, ya sea de un terreno adquirido por un individuo o de un país entero. Una vez introducidos estos rituales y los nuevos actos jurídicos en los Andes fueron adoptados casi de inmediato por la población indígena, como se desprende de la documentación de archivo 5 .

Entre los rituales políticos precolombinos, aquellos que se habían llevado a cabo por el bienestar del soberano y del Estado inca, habían perdido su razón de ser. Al dejar de existir el Estado incaico, consecuentemente cesaron también sus rituales (Gareis, 1987: 136-137). Sin embargo, en algunos casos se dio una coincidencia entre rituales precolombinos y coloniales, por ejemplo, en cuanto a la fecha o también el sentido de la ceremonia. Entre estos rituales cuyas versiones coloniales mostraron ciertas semejanzas con sus contrapartes del tiempo precolombino figuró, por ejemplo, la comunicación con el soberano regulada por un complejo ritual. Se suponía que tanto la soberanía del inca como también la del monarca español se basaba en y era legitimada por la religión. Por esta calidad numinosa atribuida a cada uno de dichos soberanos, era necesario tomar precauciones al comunicarse con ellos6. También, con ocasión de la muerte de un soberano y del acceso al trono de su sucesor, se realizaban rituales especiales. El periodo de transición de un soberano a otro

4 Acerca de la repartición de tierras en el imperio de los incas, véanse especialmente los trabajos de Moore (1958: 17-47), Murra (1979) y Schaedel (1978: 295).

5 Para marcar la transición de una propiedad de tierras de una persona a otra, el nuevo proprietario se dirigía al terreno acompañado de testigos y escribano, se paseaba por su propiedad, cortaba ramos de los árboles, levantaba un poco de tierra o algunas piedras y las tiraba a otra parte. Numerosos documentos reproducen este ritual de toma de posesión. Así, por ejemplo, se encuentra un traslado de la toma de posesión de unas viñas en el valle de Nazca en el año 1578 («Autos sobre la visita que se hizo en la hacienda de Gariyanes de la Paba y sus herederos y demas Posehedores dellas», Año 1644, fragmento sin foliación completa, Archivo Histórico del Arzobispado de Lima, Sección Papeles Importantes Leg. 1, Exp. 29, f. 1673v). De manera muy parecida, Colón ya había tomado posesión de las Indias en nombre de los Reyes Católicos en el año 1492 (Colón, 1984: 29-30). Morales Padrón (1955: 327-337) estudia detenidamente la historia de la ceremonia y detecta sus antecedentes en una fusión de elementos del Derecho Romano con el Germánico (1955: 329).

6 Pfandl (1938: 135-137) resaltó en su biografía de Felipe II que la calidad numinosa, considerada como un rasgo característico de los monarcas españoles en esta época, llevó en última instancia al aislamiento del soberano, puesto que se le atribuían tanto efectos positivos, como también negativos para los súbditos. Por lo tanto, este poder numinoso de los monarcas aseguraba el bienestar del pueblo y al mismo tiempo representaba cierto peligro para los súbditos al entrar en contacto con el soberano. Según la interpretación de Pfandl (1938: 120-132), la ambivalencia atribuida al poder numinoso se originó en un pensamiento arcaico vigente en esta época en España. Nieto Soria (1998: 110-111, 117-119), en cambio, detecta los orígenes de estas ideas en la profunda religiosidad del pueblo y de las élites que se hace notar en Castilla desde la Edad Media. Checa Cremades (1998: 101-102) explora la relación entre la sacralización del monarca y la idea del «soberano oculto» ejemplificada especialmente por Felipe II. En el caso del soberano incaico el poder numinoso resulta todavía más claro, ya que fue considerado «hijo del Sol», y por lo tanto fue visto como descendiente de una de las deidades más importantes del panteón andino (Gareis, 1987: 27). 
fue considerado en ambas sociedades como un momento liminal y de crisis7. Según las teorías de Gennep y Turner, semejantes periodos de crisis requieren la efectuación de rites de passage, es decir ritos de transición.

Además de los rituales de sucesión al trono, que ostentan los rasgos característicos de ritos de transición, los rituales coloniales de este tipo los constituyeron los autos de fe de la Inquisición. Estos sin embargo, carecen de interés en dicho ámbito, puesto que los indígenas peruanos fueron exentos de su jurisdicción ${ }^{9}$. En cambio, hubo otras festividades coloniales que contaban con masiva participación indígena. Entre éstas, resalta el Corpus Christi por su enorme popularidad en todas las capas de la sociedad colonial. Instituida por una bula papal en el año 1264, la fiesta del Corpus muy pronto adquirió gran importancia en los países europeos. En 1316 se introdujeron las procesiones como elemento festivo, que contribuyeron en gran medida a la popularidad de esta fiesta en los niveles populares de la población10.

Desde su creación, la fiesta del Corpus siempre había tenido aspectos políticos. Sin embargo, con la reforma luterana y la posterior Contrarreforma, adquirió un nuevo sentido. Del triunfo de la eucaristía, entendido como triunfo de la vida sobre la muerte, el Corpus se transformó en una fiesta emblemática del catolicismo y de las monarquías católicas. De esta manera, la celebración del Corpus se convirtió en una manifestación del sentido diferente que el catolicismo otorga a la eucaristía11.

Las procesiones, con la asistencia de todas las capas de la sociedad y sobre todo las representaciones dramáticas que formaban parte de las festividades (y que incluían también comedias), atraían mucha gente. Además, durante la época colonial, la procesión contaba en España con diversos elementos burlescos, entre los cuales figuraban actores disfrazados de animales y diablitos, los «gigantes» y en especial la Tarasca, una enorme figura de dragón, montada sobre un carro. Encabezaban la procesión actores con máscaras de animales y de seres fantásticos. Acompañadas por una banda de música que tocaba

7 Para estos ritos puede servir como ejemplo un documento del año 1557 que describe las fiestas de sucesión al trono de Felipe II celebradas en el Cusco. El manuscrito conservado en el Archivo de Indias relata de manera muy detallada cómo se celebró la fiesta en la antigua capital del imperio incaico («Fiesta y acto solemne», Cuzco 1557. F. 3, Archivo General de Indias, Audiencia de Lima 110).

8 Estos constan de tres fases: en la primera fase se efectúan los ritos de separación, es decir separación del estado social o de la situación social actual, en la que se encuentra un individuo o una sociedad. La segunda fase es la fase liminal que presenta el momento más difícil, porque se trata de un estado intermedio, en el cual el individuo o la sociedad ya no pertenece al estado social anterior, pero aun no ha entrado en su nuevo estado. Recién la tercera fase, constituida por los ritos de incorporación, instala al individuo o a la sociedad en su nuevo estado (Gennep, 1960: 3-4, 10-11, 110-113, 147-148, 178-184, 187). Turner (1969: 96-97, 106-110, 125-130) enfatiza la fase liminal que por un lado está caracterizada como un momento de crisis, dado que en este lapso de tiempo la vida social carece de estructura. Por otro lado, la fase liminal de los ritos de transición también está marcada por su fuerza creativa y de cohesión que fomenta en el grupo social que está pasando por esta fase transitoria. Según Turner los integrantes del grupo forman la communitas, es decir constituyen una unidad o un núcleo especial de personas porque comparten el mismo estado social.

9 El tribunal de la Inquisición fue instituido en Lima en 1570 y funcionó hasta 1818 (Gareis, 2006: 894; Hernández Aparicio, 1993: 390). La situación era diferente en la institución de la Extirpación de idolatrías erigida como una especie de Inquisición para indígenas en el virreinato del Perú a principios del siglo XVII. Esta institución fue creada expresamente para ocuparse de las causas de fe relativas a la población indígena (Duviols, 1971: 217-218; 1986: XXXI-XXXIII; Gareis, 1989: 55, 58; 1999: 231; 2003: 246-247).

10 Con respecto al desarrollo y al simbolismo de la fiesta del Corpus, véanse Boholm (1990: 241-245, 254-261, 273-274), Dean (1999: 7-9), Muir (1997: 67-70, 147-152). Wagner (1986: 96-125) se dedica a estudiar la eucaristía como símbolo central del pensamiento europeo de la Edad Media hasta la época moderna. Very (1962) analiza las particularidades del Corpus Christi en la Península ibérica.

11 Acosta de Arias Schreiber (1997: 57), Caillavet (1997), Dean (1999: 8) y Muir (1997: 204-206) resaltan la creciente importancia de la fiesta del Corpus como consecuencia de la Contrarreforma. 
canciones populares y alegres, las máscaras bailaban y brincaban. Aunque la Tarasca en cierta manera representaba el mal, en realidad más bien parece haber contribuido al entretenimiento de los espectadores. Mediante una compleja estructura mecánica en el interior de la figura, la Tarasca era capaz de mover la cabeza, abrir la boca y echar humo por las narices. A mediados del siglo XVII, la Tarasca del Corpus en Lima disponía de varias cabezas que se movían para alcanzar a los espectadores (Acosta de Arias Schreiber, 1997: 57-62; Ramos Sosa, 1992: 204-215). Todos los diferentes grupos de la población colonial participaban en la fiesta. Así por ejemplo, en la fiesta del Corpus limeño de 1659 se juntaron dos mil indígenas en la Plaza de Armas para librar una batalla ritual, en la cual luchaba un «Inca Rey» contra otros dos «Reyes» ${ }^{12}$.

Es muy sugestiva la intervención de las élites andinas en estas festividades. Ya a mediados del siglo XVI, se celebraron grandes fiestas del Corpus en todas las ciudades del virreinato. En estas ocasiones se estrenaban también obras dramáticas que giraban en torno a la Conquista y a la muerte del Inca. Algunas de aquellas obras fueron incluso representadas en quechua. Se hace notar que los curacas o autoridades indígenas desempeñaron un papel importante en estas fiestas (Alcina Franch, 1986: 154-155). El protagonismo de las autoridades andinas, desde luego, aún no es tan notorio como lo fue en las fiestas del Corpus del Cusco en la segunda mitad del siglo XVII. La intervención de un grupo de curacas cuzqueños quedó documentada en una serie de quince cuadros pintados hacia 1675, según la datación de Gisbert (1994: 98). Se desconoce quién fue el autor o los autores de los óleos, aunque lo más probable es que fueron uno o varios pintores de la escuela cuzqueña, la cual floreció justo en esa época. Dean (1999: 77-78), por ejemplo, los atribuye a dos pintores distintos; uno de ellos puede haber sido Juan Zapaca Inga13.

Es significativo el hecho que este grupo de cinco curacas hubiera encargado los cuadros, lo cual sugiere que siguieron un plan para un programa de auto-representación al encomendar estos óleos. Este programa de representación íconográfica incluía también otros tipos de retratos. Así por ejemplo, las élites andinas frecuentemente se hicieron retratar como donantes de imágenes ${ }^{14}$. En primer lugar, este tipo de representación permitía demostrar la buena situación económica de la persona donante, ya que estos cuadros eran muy costosos. De modo que colocaba a la élite andina en el mismo nivel que las élites española y criolla. Además, los íconos de donantes también señalaban la privilegiada posición social de la persona y su rol de buen cristiano que cumplía con sus obligaciones religiosas. Y por último, los donantes aparecían en estos cuadros en la inmediata vecindad del santo o de la santa, de modo que el retrato del donante formaba parte integral de la santa escena, lo que garantizaba la presencia del donante en el espacio público y sagrado de la iglesia 15.

Los cuadros del Corpus cuzqueño fueron pintados, según parece, para la iglesia parroquial de los curacas. Es decir estos íconos cumplieron por un lado con las funciones de retratos de donantes, y por otro lado subrayaron el protagonismo de los curacas en una de las

12 Documento citado en Flores Galindo (1988: 60). Acosta de Arias Schreiber (1997: 58) relata que los participantes de descendencia africana se ocuparon de contribuir con música y baile a la fiesta y también elegían un «rey» con su séquito para la procesión del Corpus.

13 El autor o los autores de los cuadros también podrían haberse orientado en las obras de Diego Quispe Tito (1611¿1681?) que fue el pintor más importante de la escuela cuzqueña o de Basilio Santa Cruz Pumacallao (¿Cusco? 1699/1700 Cusco) y su taller. Dean (1999: 77-78) Ilama la atención sobre el hecho que cuadros anónimos al estilo de la escuela cuzqueña se atribuyeron frecuentemente a Quispe Tito o a Santa Cruz Pumacallao.

14 Es de notar que las élites andinas encomendaron gran cantidad de estos retratos de donantes, incluso más que los españoles del Perú en esa época (Mesa \& Gisbert, 1982, t. 1: 286-287). Algunos de estos retratos costosísimos fueron de cuerpo entero y labrados totalmente en plata (Gisbert, 1994: 97; Saignes, 1987).

15 Sobre las ideas relacionadas con los cuadros de donantes andinos, véase Gisbert (1994: 92-99). 
fiestas coloniales más importantes. La diferencia entre las representaciones de los donantes individuales y las del Corpus es notoria: los retratos de donantes individuales muestran a esta persona en su rol de buen feligrés, generalmente adorando la santa imagen, mientras que los cuadros del Corpus documentan la posición destacada de los curacas en la sociedad colonial. Al igual que las autoridades coloniales, ellos también cumplen con funciones importantes en el evento. No pertenecen a los espectadores, sino que desempeñan un papel activo y de primer plano. Al señalar el protagonismo de los curacas cuzqueños en la celebración del Corpus, los cuadros también encierran un mensaje sobre el rol político de la élite andina y su posición en la jerarquía de los cargos virreinales (fig. 1)16.

A través de los vestidos que lucen en los óleos, los curacas del Cusco hicieron referencia al imperio de los incas: visten un inca-unku, es decir una túnica incaica, desde luego modificada al estilo colonial, en combinación con elementos españoles, como, por ejemplo, las mangas bordadas con encaje17. El traje híbrido que lucen en los óleos resalta visualmente la fusión de elementos y de símbolos de ambas culturas. A través de las imágenes encargadas por los curacas salta a la vista que el Corpus del Cusco no fue idéntico a la misma fiesta en Lima o en otras ciudades de la costa peruana. También en las ciudades de la costa intervinieron indígenas y descendientes de los diferentes grupos socio-culturales en las fiestas del Corpus, pero obviamente los curacas de la población indígena costeña no jugaron el mismo papel que los cinco curacas que encargaron los cuadros del Cusco (fig. 2).

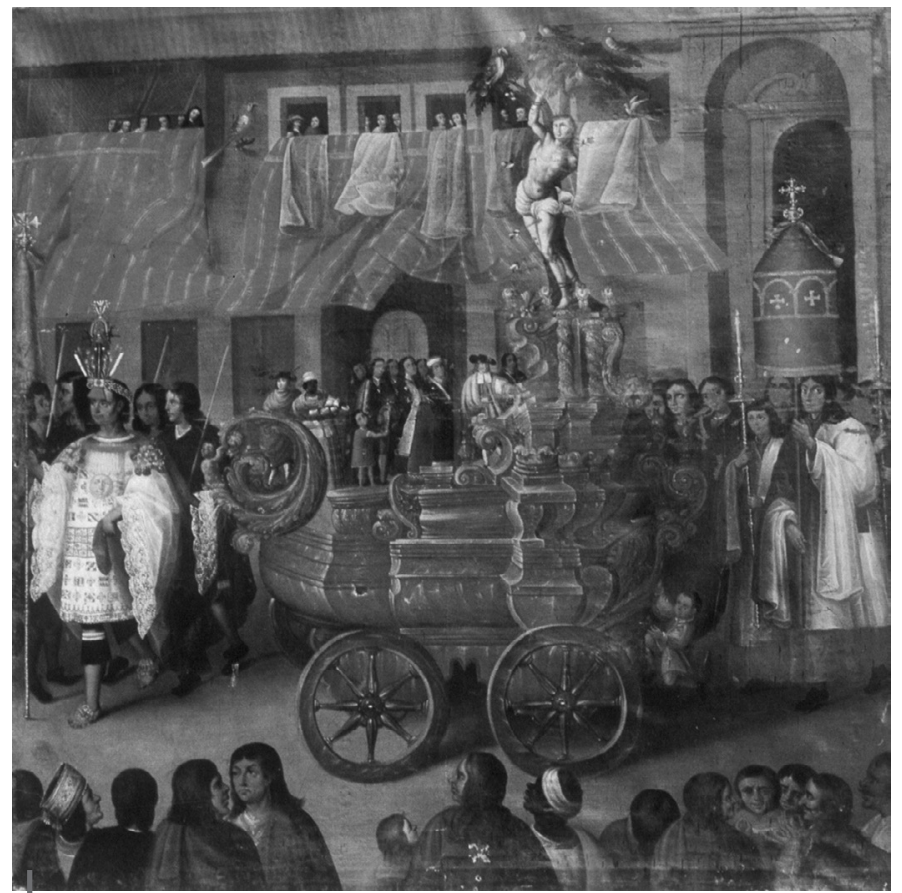

Figura 1 - El cacique de San Sebastián en la procesión de Corpus

Museo Virreinal de Cuzco. Tomado de Acosta de Arias Schreiber (1997: portada)

Si comparamos descripciones de las fiestas de Corpus Christi en otras ciudades de la monarquía española, se notan paralelos y diferencias. Como en otras partes del mundo hispano, en los cuadros del Cusco casi no aparecen mujeres, solamente se ven algunas pocas señoras observando la procesión desde los balcones y umbrales de las casas

16 Véanse también las consideraciones de Cummins (1991: 209) acerca de la representación de los curacas andinos en los cuadros del Corpus cuzqueño.

17 Gisbert (1994: 98-99) estudia detenidamente la vestimenta de los curacas en los cuadros del Corpus cuzqueño. Además, hace notar las transformaciones de los vestidos usados en los retratos de autoridades andinas que al parecer se produjeron poco después de terminar la serie del Corpus, es decir hacia 1690-1700. De todos modos, este proceso de transformación debió haberse consumido hasta la década de los años 30 del siglo XVIII, puesto que los curacas representados en una serie de cuadros pintados en esa época estrenan otro tipo de vestimenta.

18 Compárense los cuadros publicados por Dean (1999: 20, fig. 1; 65, fig. 8; 66, fig. 9; 67, fig. 10; 68, fig. 11; 69, fig. $12 ; 70$, fig. $13 ; 71$, figs. $14-15 ; 72$, fig. $16 ; 73$, figs. $17-18 ; 74$, fig. $19 ; 75$, fig. $20 ; 76$, fig. 21 ). 


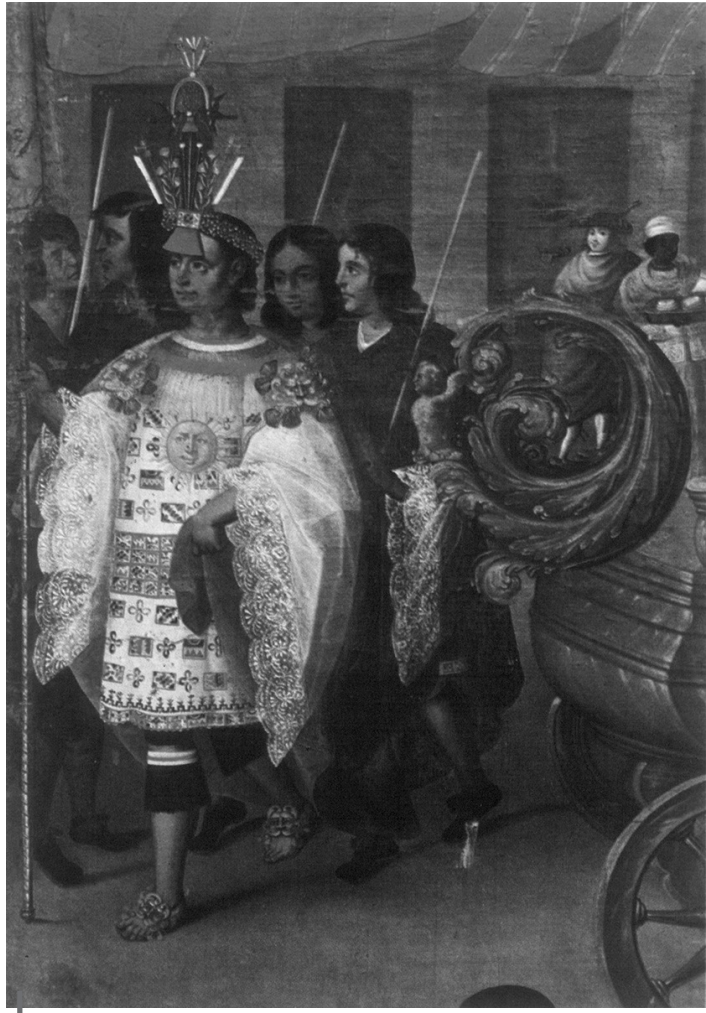

Figura 2 - El cacique de San Sebastián, luciendo un traje festivo andino colonial, corona inca al estilo colonial y pectoral de sol (detalle)

Museo Virreinal de Cuzco. Tomado de Gisbert (1994: 152-153)
- o sea desde el margen del evento18-. Sin embargo, no se encuentran en los óleos cuzqueños referencias a los elementos burlescos que tanto gustaban al público de Lima, y que las autoridades eclesiásticas nunca lograron suprimir de la celebración del Corpus limeño. En muchas partes fueron especialmente los elementos burlescos como los gigantes y la Tarasca lo que fomentó la apropiación de la fiesta del Corpus por parte de las capas populares de la sociedad. Todo esto sugiere que el Corpus del Cusco tenía un carácter distinto de la festividad homónima celebrada en otras ciudades del virreinato.

Varios autores interpretaron la especial configuración de la fiesta del Corpus cuzqueño. Gisbert (1992: 148, 150; 1994: 98-99) enfatizó la continuidad de símbolos desde la época precolombina. Resaltó también la cercanía de la fecha de la fiesta del Corpus con la del Inti Raymi, y sobre todo el omnipresente simbolismo del sol, tanto en la fiesta precolombina dedicada al sol como en el Corpus colonial del Cusco19. Al igual que el Inti Raymi en el Incanato, el Corpus Christi colonial era una de las fiestas más importantes del ciclo anual. Desde este punto de vista, las múltiples referencias al sol en los trajes y atuendo de los curacas cuzqueños se pueden interpretar como reafirmación del culto solar, el cual ya había jugado un papel importante en las religiones andinas anteriormente a los incas. Por otro lado, las referencias al sol igualmente pueden ser vistas como alusiones al imperio incaico, lo cual en la antigua capital del imperio, no sería nada sorprendente. Sin embargo, con esto no quiero sugerir que la fiesta del Corpus haya sido una prolongación del Inti Raymi, ni de ninguna otra fiesta incaica, más bien saltan a la vista varios elementos compartidos por las fiestas precolombinas y coloniales. Con mucha probabilidad, en esta época ya no se trataba de una continuación de los modelos festivos del imperio inca, sino más bien de una inspiración que las fiestas coloniales tomaron de las festividades incaicas.

Zuidema (1993: 341-346, 368-371; 1996: 179-185), a su vez, se ocupa de la pregunta: ¿cuál podía haber sido la fiesta precolombina más cercana a ser un antecedente de estas celebraciones coloniales en Cusco? Llega a la conclusión que en el pensamiento de la población autóctona, poco a poco, la fiesta del Corpus fue relacionada con una fiesta precolombina de la cosecha celebrada varias semanas antes. El autor adelanta una serie de argumentos en apoyo de su hipótesis resaltando la figura de la Tarasca como elemento clave. En este contexto es muy sugerente analizar el papel de esta figura en las celebraciones del catolicismo hispano, tomando en consideración su vínculo estrecho con el mundo

19 Acosta de Arias Schreiber (1997: 57-62) menciona varias fuentes históricas que igualmente constataron paralelos y coincidencias entre la celebracion del Corpus colonial y la fiesta del Inti Raymi en la época precolombina. 
femenino y en especial con un importante personaje de la mitología andina, la mujer guerrera, transgresora de las reglas sociales.

Otra línea de interpretación es proporcionada por Dean (1999: 7-8, 15-16, 23, 32), que enfoca el papel de los curacas andinos en el Corpus desde el punto de vista del poder colonial. Desde esta perspectiva, la fiesta del Corpus se puede interpretar como una celebración del triunfo del Catolicismo sobre las religiones paganas y del triunfo de los españoles sobre los pueblos indígenas. Aunque esta visión de los hechos muy bien puede haber sido la de las autoridades coloniales, a mi modo de ver, los curacas cuzqueños no necesariamente compartieron esta interpretación del evento. No hay que olvidar el hecho que en esa época ellos se consideraban cristianos y por lo tanto la fiesta del Corpus que celebraba el triunfo de Jesucristo y de la eucaristía no debe haber chocado con sus pensamientos religiosos. Más probablemente, la fiesta del Corpus encerraba mensajes polisémicos, interpretados de manera diferente por los diversos integrantes del ritual. Si bien para las autoridades coloniales la participación de los curacas tenía cierto significado, para los curacas, en cambio, el significado era distinto. La festividad les proporcionaba sobre todo un espacio para la escenificación de su rol en la sociedad colonial, tal como lo veían ellos. En los cuadros se plasma el hecho que los curacas cuzqueños asumieron el papel de dirigentes indígenas con cargos obtenidos en el Estado colonial. Desde su punto de vista, ellos eran autoridades coloniales a la par que los otros funcionarios de la jerarquía política virreinal. En este rol se hicieron retratar como manifestación de su elevada posición social. Los cuadros del Corpus cuzqueño, por lo tanto, sirvieron tanto como documentación del papel de los curacas en la fiesta, como también de afirmación de su importante rol en la sociedad colonial. La utilización de una fiesta religiosa y a la vez de un ritual colonial para fines propagandísticos en su propio interés, demuestra, en mi opinión, que los curacas cuzqueños se sirvieron con sutileza de los medios proporcionados dentro del sistema colonial. Vale decir que utilizaron los propios medios introducidos por el Estado colonial, ya que la fiesta del Corpus asignaba a cada participante, mediante una escenificación codificada, su sitio en la sociedad. Al presentarse junto a las autoridades coloniales como protagonistas de las festividades, confirmaban el poder colonial, pero al mismo tiempo afirmaban su liderazgo de la República de los indios (fig. 3).

\section{CONCLUSIÓN}

El estudio de la vida ceremonial del virreinato peruano muestra que el poder colonial otorgaba mucha importancia a los rituales políticos y en especial a las grandes festividades públicas. Queda patente, además, la semejanza entre los sistemas

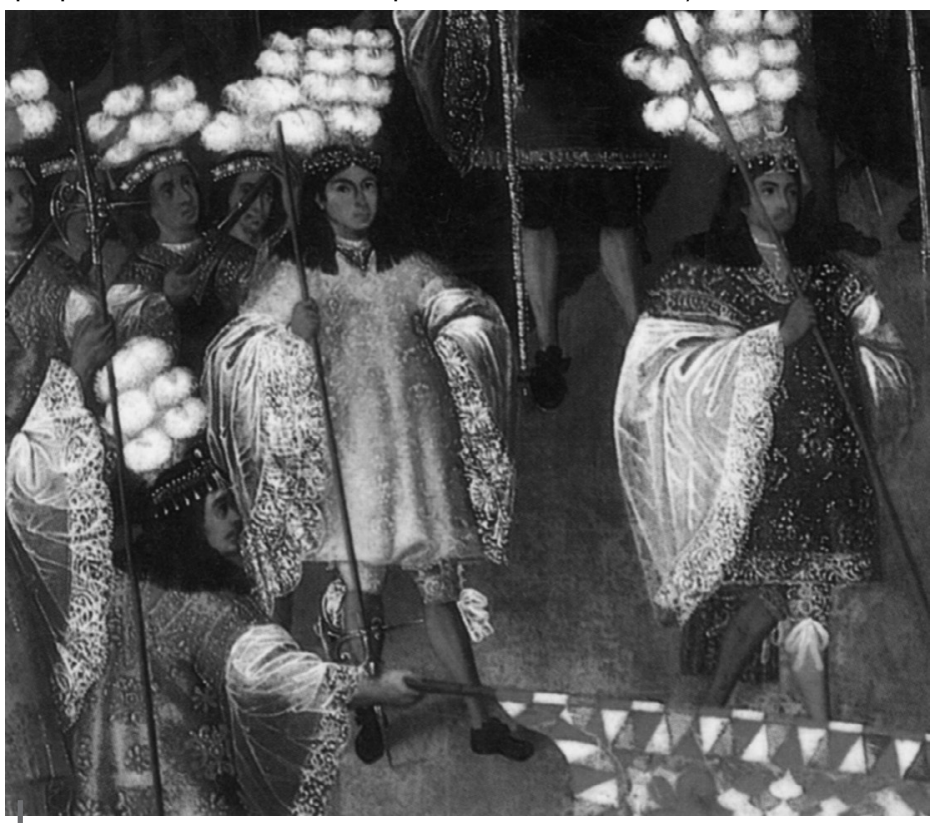

Figura 3 - Final de la procesión: la guardia andina de la ciudad (detalle) Tomado de Ramos Sosa (1992: lám. 63) 
festivos del Incanato y de la Colonia. También el papel de las autoridades andinas se asemejaba bastante en ambos sistemas gubernamentales, ya que ellos fueron los ejes entre el soberano inca o el Virrey y sus respectivos grupos étnicos. Cumpliendo con su función de intermediarios entre los centros de poder y los pueblos indígenas, fueron ellos quienes reclutaban la mano de obra para las diversas empresas del estado incaico y posteriormente del Estado colonial. Por eso, los curacas jugaron un rol de suma importancia en la organización económica del virreinato peruano. Consecuentemente muchas medidas del Estado colonial apuntaban en especial a la integración de las élites autóctonas en el sistema colonial. Entre estas medidas figuraba por ejemplo la educación de los hijos de las autoridades andinas que a partir de principios del siglo XVII se llevó a cabo en colegios especiales (Alaperrine-Bouyer, 2002; Gareis, 2007: 161-166). Como resultado de esta política colonial de asimilación parcial de las élites autóctonas paulatinamente se iban formando nuevas prácticas culturales entre los curacas andinos. Una de estas novedades fue la adopción de la tradición europea de encomendar retratos individuales. Al igual que las élites en España, las autoridades andinas se hicieron retratar para demostrar su elevada posición social. Es decir, adoptaron una práctica cultural europea para sus propios fines.

De manera parecida también se servían de la cultura festiva de la Colonia, lo cual resalta con particular claridad en las intervenciones de las élites andinas durante las fiestas del Corpus. Con ocasión de esta festividad, todas las ciudades del virreinato realizaban costosas ceremonias para celebrar el triunfo de Cristo sobre la muerte. Era, pues, una fiesta alegre que invitaba la población a regocijarse. En Lima y otros lugares del virreinato peruano - así como en España - los elementos carnavalescos de la fiesta atraían las masas populares. El Corpus se festejaba entonces con gran concurso de gente, el estreno de obras dramáticas y otras diversiones. También intervinieron las autoridades indígenas en diferentes ocasiones. En Lima, armaron por ejemplo en una representacion teatral una batalla entre varios «Reyes incas» con su séquito involucrando miles de actores. Los cuadros encargados por los cinco curacas del Cusco, en cambio, presentan una visión diferente de la fiesta del Corpus, puesto que aquí el evento aparentemente carece de los elementos burlescos. Según este conjunto de cuadros, el Corpus en la antigua capital del Incanato se celebraba con gran solemnidad y en total estos íconos transmiten una sensación de profunda religiosidad, compartida por todos los participantes. Es de pensar, sin embargo, que estos óleos no relatan lo que pasó en esta fiesta del Corpus, sino que la narración más bien intenta presentar el papel de los cinco curacas tal como ellos lo querían ver. Por eso, es posible que el protagonismo de las cinco autoridades andinas en la fiesta colonial, reflejado por los cuadros, quizás no fuera tan pronunciado. Por otro lado, su verdadera actuación en la fiesta colonial carece de importancia aquí, ya que mediante esta serie de cuadros de todas maneras lograron su objetivo de presentarse como protagonistas del evento. De modo que se servían con sutileza de una nueva práctica cultural introducida por los españoles al adoptar este tipo de auto-representación mediante una serie de cuadros narrativos estrenados en un lugar público. En adición a esto, las pinturas de la fiesta cuzqueña ponen de relieve que las élites andinas utilizaron los rituales políticos del Estado colonial para reafirmar su propia posición sociopolítica como descendientes y herederos de los soberanos incas y como dirigentes de la población indígena. Finalmente, los cuadros también hacen referencia al protagonismo de los curacas en el campo religioso, mostrándolos como actores de primer plano en una de las fiestas más importantes de la monarquía católica. 


\section{Referencias citadas}

ACOSTA DE ARIAS SCHREIBER, R. M., 1997 - Fiestas coloniales urbanas (Lima, Cuzco, Potosí), 208 p.; Lima: Otorongo.

ALAPERRINE-BOUYER, M., 2002 - Saber y poder: la cuestión de la educación de las elites indígenas. In: Incas e indios cristianos. Elites indígenas e identidades cristianas en los Andes coloniales (Jean-Jacques Decoster, ed.): 145-167; Cuzco: IFEA, Centro Bartolomé de las Casas. Travaux de I'Institut Français d'Etudes Andines 149. Archivos de Historia Andina 38.

ALCINA FRANCH, J., 1986 - Teatro y parateatro: teatro quechua. In: Teatro y fiesta en el barroco. España e Iberoamérica (José María Díez Borque, ed.): 153-170; Barcelona: Ediciones del Serbal.

BELL, C., 1997 - Ritual: Perspectives and Dimensions, 351 p.; New York, Oxford: Oxford University Press.

BIZEUL, Y., 2000 - Theorien der politischen Mythen und Rituale. In: Politische Mythen und Rituale in Deutschland, Frankreich und Polen (Yves Bizeul, ed.): 15-39; Berlin: Duncker \& Humblot. Ordo Politicus 34.

BOHOLM, A., 1990 - The Doge of Venice: the symbolism of State Power in the Renaissance, 298 p.; Göteborg: Institute for Advanced Studies in Social Anthropology (IASSA), University of Gothemburg.

BOHOLM, Å., 1996 - Introduction. In: Political Ritual (Åsa Boholm, ed.): 1-13; Göteborg: Institute for Advanced Studies in Social Anthropology (IASSA), University of Gothenburg.

CAILLAVET, C., 1990 - Rituel espagnol, pratique indienne : I'occidentalisation du monde andin par le spectacle des institutions coloniales. In : Structures et Cultures des Sociétés Ibéro-américaines. Au-delà du modèle socio-économique, Hommage au Professeur François Chevalier: 25-40; Bordeaux: Ed. CNRS.

CAILLAVET, C. 1997 - Festivals of the Northern Andes: the Origins and Metamorphoses of Rituals of Aggression. In: Studies Presented to Reiner Tom Zuidema. Journal of The Steward Anthropological Society (Gary Urton \& Deborah Poole, eds.), vol. 25: 143-178; Illinois.

COLÓN, C., 1984 - Textos y documentos completos. Relaciones de viajes, cartas y memoriales (Consuelo Varela, ed.), 381 p.; Madrid: Alianza Editorial.

CUMMINS, T. B. F., 1991 - We Are the Other: Peruvian Portraits of Colonial Kurakuna. In: Transatlantic Encounters. Europeans and Andeans in the Sixteenth Century (Kenneth J. Andrien \& Rolena Adorno, eds.): 203-231; Berkeley: University of California Press.

CHECA CREMADES, F., 1998 - Monarchic Liturgies and the «Hidden King»: The Function and Meaning of Spanish Royal Portraiture in the Sixteenth and Seventeenth Centuries. In: Iconography, Propaganda, and Legitimation (Allen Elenius, ed.): 89-104; Oxford: European Science Foundation, Clarendon Press. The Origins of the Modern State in Europe, Theme G.

DEAN, C., 1999 - Inka Bodies and the Body of Christ. Corpus Christi in Colonial Cuzco, Peru, 288 p.; Durham, London: Duke University Press.

DUVIOLS, P., 1971 - La lutte contre les religions autochtones dans le Pérou colonial. L'extirpation de l'idolâtrie entre 1552 et 1660, 428 p.; Lima: Institut Français d'Études Andines. Travaux de l'Institut Français d'Études Andines 13. 
DUVIOLS, P., 1986 - Cultura andina y represión. Procesos y visitas de idolatrías y hechicerías (Cajatambo, siglo XVII), 570 p.; Cusco: Centro Bartolomé de las Casas. Archivos de Historia Andina 5.

FIESTA, 1557 - Fiesta y acto solemne, 3 f., leg. 110; Archivo General de Indias: Audiencia de Lima.

FLORES GALINDO, A., 1988 - Buscando un inca, 439 p.; Lima: Editorial Horizonte.

GAREIS, I., 1987 - Religiöse Spezialisten des zentralen Andengebietes zur Zeit der Inka und während der spanischen Kolonialherrschaft, 519 p.; Hohenschäftlarn: Klaus Renner Verlag. Münchner Beiträge zur Amerikanistik 19.

GAREIS, I., 1989 - Extirpación de idolatrías e Inquisición en el virreinato del Perú. Boletín del Instituto Riva-Agüero, 16: 55-74; Lima.

GAREIS, I., 1999 - Repression and cultural change: the «Extirpation of Idolatry» in colonial Peru. In: Spiritual Encounters: Interactions between Christianity and native religions in colonial America (Nicholas Griffiths \& Fernando Cervantes, eds.): 230-254; Birmingham: University of Birmingham Press, University of Nebraska Press.

GAREIS, I., 2003 - Die Geschichte der Anderen. Zur Ethnohistorie am Beispiel Perus (15321700), 328 p.; Berlin: Reimer Verlag.

GAREIS, I., 2006 - Peru. In: Encyclopedia of Witchcraft. The Western Tradition (Richard M. Golden, ed.): vol. III, 894-896; Santa Barbara: ABC, CLIO.

GAREIS, I., 2007 - Koloniale Bildungspolitik und indigene Eliten in Peru. Jahrhundert: Das Kazikenkolleg in Lima. In: Frühneuzeitliche Bildungsgeschichte der Reformierten in konfessionsvergleichender Perspektive. Schulwesen, Lesekultur und Wissenschaft (Heinz Schilling \& Stefan Ehrenpreis, eds.): 161-181; Berlin: Duncker \& Humblot. Zeitschrift für Historische Forschung Beiheft 38.

GENNEP, A. van, 1960 - The Rites of Passage, 198 p.; London: Routledge, Kegan Paul. Traducción de Monika B. Vizedom \& Gabrielle L. Caffee

GISBERT, T., 1992 - The Indigenous Element in Colonial Art. In: America. Bride of the Sun. 500 years Latin America and the Low Countries: 143-155; Gent: Ministry of the Flemish Community, Imschoor. Royal Museum of Fine Arts Antwerp.

GISBERT, T., 1994 - IConografía y mitos indígenas en el arte, 250 p.; La Paz: Línea Editorial, Fundación BHN, Editorial Gisbert.

HERNÁNDEZ APARICIO, P., 1993 - La actividad procesal en la Inquisición de Lima: 15701818. In: Los Inquisidores: 387-406; Vitoria-Gasteiz: Fundación Sancho el Sabio.

LIENHARD, M., 1992 - La voz y su huella. Escritura y conflicto étnico-cultural en América Latina (1492-1988), 305 p.; Lima: Editorial Horizonte. Crítica Literaria 9.

MESA, J. DE \& T. GISBERT, 1982 - Historia de la pintura cuzqueña, t. 1: 317 p., t. 2: 338830 p.; Lima: Fundación Augusto N. Wiese, Banco Wiese. Biblioteca peruana de cultura.

MORALES PADRÓN, F., 1955 - Descubrimiento y toma de posesión. Anuario de Estudios Americanos, XXI: 321-380; Sevilla.

MOORE, S. F., 1958 - Power and Property in Inca Peru, 190 p.; New York: Columbia University Press.

MUIR, E., 1997 - Ritual in Early Modern Europe, 291 p.; Cambridge: Cambridge University Press. New Approaches to European History 11.

MURRA, J. V., 1979 - Derechos a las tierras en el Tawantinsuyu. Revista de la Universidad Complutense, 28 (117): 237-262; Madrid. 
MURRA, J. V., 1982 - The Mit'a Obligations of Ethnic Groups to the Inka State. In: The Inca and Aztec States, 1400-1800. Anthropology and History (George A. Collier, Renato I. Rosaldo, John D. Wirth, eds.): 237-262; New York: Academic Press.

NIETO SORIA, J. M., 1998 - Propaganda and Legitimation in Castile: Religion and Church, 1250-1500. In: Iconography, Propaganda, and Legitimation (Allen Elenius, ed.): 105-119; Oxford: European Science Foundation, Clarendon Press. The Origins of the Modern State in Europe, Theme G.

OBEREM, U., 1990 - Die Conquista und Indianer unter spanischer Herrschaft. In: Altamerikanistik. Eine Einführung in die Hochkulturen Mittel- und Südamerikas (Ulrich Köhler, ed.): 493-517; Berlin: Dietrich Reimer.

PFANDL, L., 1938 - Philipp II. Gemälde eines Lebens und einer Zeit, 568 p.; München: Verlag Georg D. W. Callwey.

POLO DE ONDEGARDO, J., 1916 [1571] - Relación de los fundamentos acerca del notable daño que resulta de no guardar a los indios sus fueros. Junio 26 de 1571. In: Informaciones acerca de la religión y gobierno de los incas (Carlos A. Romero, ed.), t. III: 45-188; Lima: Imprenta y Librería Sanmartí. Colección de Libros y Documentos para la Historia del Perú.

RAMOS SOSA, R., 1992 - Arte festivo en Lima virreinal (siglos XVI-XVII), 294 p.; Sevilla: Junta de Andalucía, Consejería de Cultura y Medio Ambiente, Asesoría Quinto Centenario.

SAIGNES, T., 1987 - De la borrachera al retrato: los caciques andinos entre dos legitimidades (Charcas). Revista Andina, 5(9): 139-170; Cusco.

SCHAEDEL, R. P., 1978 - Early State of the Incas. In: The Early State (Henrij J. M. Claessen \& Peter Skalník, eds.): 289-320; The Hague: Mouton.

SEED, P., 1995 - Ceremonies of possession in Europe's conquest of the New World, 1492-1640, 199 p.; Cambridge: Cambridge University Press.

TURNER, V. W., 1969 - The Ritual Process. Structure and Anti-Structure, 213 p.; London: Routledge, Kegan Paul.

VERY, F., G., 1962 - The Spanish Corpus Christi procession : a literary and folkloric study; Valencia.

WAGNER, R., 1986 - Symbols That Stand for Themselves, 150 p.; Chicago, London: The University of Chicago Press.

WIEDNER, D. L., 1960 - Forced Labor in Colonial Peru. The Americas, 16: 357-383; Berkeley.

ZUIDEMA, T., 1993 - De la Tarasca a Mama Huaco. In: Religions Andines et Langues indigènes. Actes du Colloque III d'Études Andines (Pierre Duviols, ed.): 331-383; Provence: Université de Provence.

ZUIDEMA, T., 1996 - Fête-Dieu et fête de l'Inca. Châtiment et sacrifice humain comme rites de communion. In : Le Corps de Dieu en fêtes (Antoinette Molinié, ed.): 175-222; París: Editions du Cerf. 